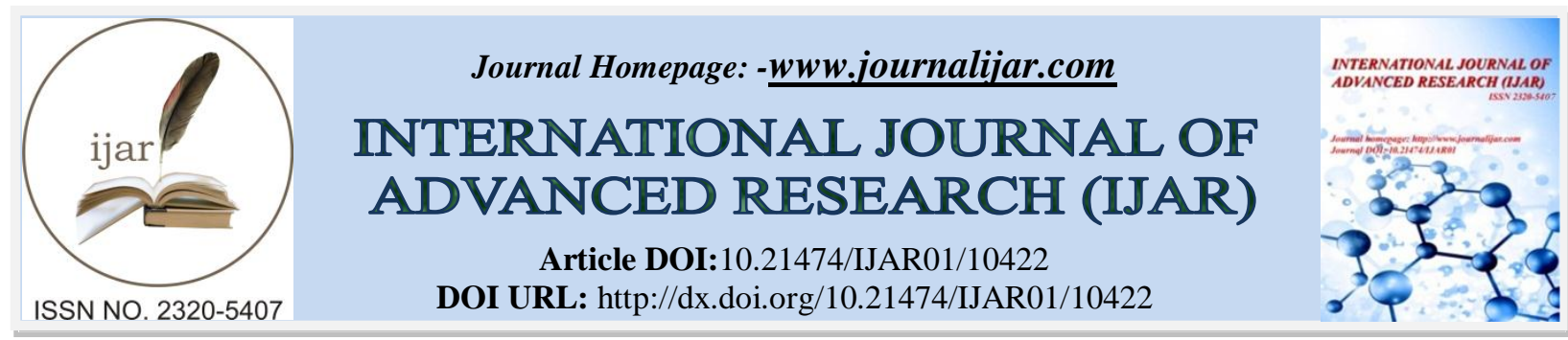

RESEARCH ARTICLE

\title{
HIGHER SERUM CA - 125 LEVELS CORRELATED WITH ADVANCING STAGING AND EXTRANODAL LESIONS IN EGYPTIAN NON - HODGKIN'S LYMPHOMA (NHL) PATIENTS
}

\author{
Ali Hasaneen ${ }^{1}$, Mohamed Ahmed ${ }^{1}$, Reem R. Abdel-Galil ${ }^{2}$ and Abdel Motaleb Mohamed ${ }^{3}$ \\ 1. Internal Medicine Department, Faculty of Medicine, Benha University, Egypt. \\ 2. Microbiology and Immunology Department, Faculty of Medicine, Benha University, Egypt. \\ 3. Clinical Oncology Department, Faculty of Medicine, Zagazig University, Egypt.
}

\section{Manuscript Info}

Manuscript History

Received: 30 November 2019

Final Accepted: 31 December 2019

Published: January 2020

Key words:-

CA-125, Non-Hodgkin's Lymphomas, Egyptian Patients

\section{Abstract}

Serum CA-125 level has been shown to be elevated in patients with non-Hodgkin's lymphomas (NHLs) and it is proposed that cytokines released by lymphoma cells activate mesothelial cells to secrete this glycoprotein.

Aim of Study: The aim was to evaluate whether serum CA-125 levels vary with extranodal extension and disease staging of Egyptian NHL patients

Patients and Methods: 117 adult patients with NHL were included, and based on the patients' available laboratory (CBC, ESR, liver enzymes, LDH), radiological (CT scans and PET scanning), and pathological (reports of biopsies obtained from affected lesions) investigations, the sites of lesions (nodal and/or extranodal), disease staging (from stage I to IV), and performance status "PS" (from PS-0 to PS-5) were determined at patients' presentation. Serum CA-125 levels were estimated for all studied patients.

Results:Mean serum CA-125 level in all studied patients was $59.2 \pm 17.8 \mathrm{u} / \mathrm{mL}$, with no significant differences between males and females. Patients with PS-3 had higher serum CA-125 levels than patients with PS-2 and PS-1. Serum CA-125 levels were significantly higher in patients presented with B symptoms $(125.9 \pm 31.2 \mathrm{u} / \mathrm{mL})$ compared to those with no B symptoms $(57.2 \pm 18.7 \mathrm{u} / \mathrm{mL})$. Serum CA125 levels showed significant positive non-linear correlation with the disease stages, where the mean serum CA- 125 levels in patients with stage-I NHL was $51.7 \pm 15.2 \mathrm{u} / \mathrm{mL}$, stage-II was $61.3 \pm 17.6 \mathrm{u} / \mathrm{mL}$, stageIII was $93.1 \pm 31.8 \mathrm{u} / \mathrm{mL}$, and stage-IV was $167.1 \pm 59.6 \mathrm{u} / \mathrm{mL}$.Mean serum CA-125 levels in patients with extranodal lesions only $(217.1 \pm 47.9 \mathrm{u} / \mathrm{mL})$ and in patients with both nodal and extranodal lesions $(198.2 \pm 41.7 \mathrm{u} / \mathrm{mL})$ were significantly higher compared to its levels in patients with nodal lesions only $(51.7 \pm 16.3 \mathrm{u} / \mathrm{mL})$.

Conclusion and Recommendations: In NHL patients, the presence of B symptoms, advancing stages of disease, and extranodal lesions were associated with higher serum C-125 levels. Further studies are recommended to set a cut-off point for using serum CA-125 levels as an indicator for NHL extranodal lesions.

Corresponding Author:- Ali Hasaneen

Address:- Internal Medicine Department, Faculty of Medicine, Benha University, Egypt. 


\section{Introduction:-}

Non-Hodgkin's lymphomas (NHLs) are a heterogenous group of lymphoproliferative malignant diseases with differing patterns of behavior and response to treatment ${ }^{[1]}$. Different types of NHLs vary in severity from indolent to aggressive lymphomas; longer survival is expected in less aggressive NHLs, while aggressive NHLs can be rapidly fatal, if not treated properly ${ }^{[2]}$. TheInternational Prognostic Index (IPI), a widely accepted prognostic tool for NHL, includes several independent prognostic factors namely B symptoms (fever, night sweats, weight loss), performance status(PS), age, serum lactate dehydrogenase (LDH) level, serum $\beta 2$-microglobulin, tumor bulk, and number of nodal and extranodal sites of disease ${ }^{[3]}$.

Cancer antigen 125 (CA-125) has been suggested to be used as a prognostic indicator for non-Hodgkin lymphomas ${ }^{[4]}$.CA-125, also known as mucin 16 or MUC16, is a $220 \mathrm{kDa}$ glycoprotein; its antigenic determinant is identified by a monoclonal antibody, OC 125 , raised against the epithelial ovarian cancer cell line OVCA $433^{[5]}$.CA125 is a product of MUC 16 gene that promotes cancer cell proliferation and inhibits anti-cancer cell immunity.CA125 has been found to be expressed by amniotic and coelomic epithelium of fetal tissue and mesothelial cells of the pleural, peritoneum, and pericardium, female genital epithelia (tubal, ovarian, endometrial, and endocervical) and mucosal epithelial of gastrointestinal tract in adult tissues ${ }^{[6]}$.

CA-125 has found application as a tumor biomarker that may be elevated in the blood of some patients with specific types of cancers or other conditions that are benign ${ }^{[4]}$. CA-125 is widely used as a tumor biomarker in epithelial ovarian cancer. However, elevation in serum CA-125 levels has also been reported in other conditions including gynecological malignancies like endometrial adenocarcinomas, fallopian tube carcinoma, other malignancies like malignant mesotheliomas, carcinomas of pancreas, colon, breast, and lung, and also non-malignant conditions like pregnancy, endometriosis, benign ovarian cysts and pelvic inflammatory disease ${ }^{[2]}$. CA-125 has been shown to be elevated in NHLs by some studies, and it is proposed that cytokines released by lymphoma cells activate mesothelial cells to secrete this glycoprotein ${ }^{[7]}$. Pui and Ludwig ${ }^{[8]}$ proposed that the lymphokines released by the tumor might represent the stimulus for CA-125 production. Thus, CA-125 could reflect the patient's response to the invasiveness potential of the tumor acting as a measure of its infiltrative activity ${ }^{[8]}$. It may also be an index of the clinically undetected extranodal extension of the $\mathrm{NHLs}^{[9]}$.

\section{Aim of study:}

The aim of this study was to evaluate the value of elevated serum CA-125 levels as an indicator for presence of extranodal lesions in Egyptian patients with non-Hodgkin's lymphomas and to study the correlation between serum CA-125 levels and various stages of NHL disease.

\section{Patients and Methods:-}

This prospective multi-centers study was conducted at Hematology/Oncology Unit, Internal Medicine Department, Benha University Hospital and Clinical Oncology Department, Zagazig University Hospital, Egypt, during the period from October, 2017 to August, 2019, respecting the ethical committee of both Benha and Zagazig University hospitals. After informing the patients about the nature of study and obtaining written consent from them, 117 adult patients with biopsy-proven newly-diagnosed non-Hodgkin's lymphomas were selected. Patients aged 18 years or more, either male or female, with various body mass indices (BMIs), and with nodal lesions, extranodal lesions, or both, were included in this study. Patients with other malignancies, women with gynecological malignancies or ovarian cysts, pregnant women, women with pelvic inflammatory diseases, and NHL patients who started chemotherapy were excluded. All the included patients were subjected to complete history taking, thorough physical examination, and their biopsies results were reviewed to confirm the pathological type of non-Hodgkin's lymphoma.

Using the already performed and available patients' investigations, including laboratory (routine laboratory testing, complete blood count "CBC", lactate dehydrogenase "LDH", liver functions tests) and radiological (computed tomography "CT" scans and positron emission tomography "PET" scanning) investigations, the sites of NHL lesions were determined. Based on the sites of lesions, the patients were categorized into 3 groups: patients with nodal lesions only (they were used as a control group), patients with extranodal lesions only, and patients with both nodal and extranodal lesions. The stages of NHL disease were categorized according to the Ann Arbor staging system ${ }^{[10]}$ : stage-I: single node or adjacent group of nodes (stage-IE: single extranodal lesion without nodal involvement); 
stage-II: multiple lymph node groups on the same side of diaphragm (stage-IIE: stage-I or stage-II nodal lesion with limited contiguous extranodal involvement); stage-III: multiple lymph node groups on both side of diaphragm (or nodes above the diaphragm with spleen involvement); and stage-IV: multiple non-contiguous extranodal sites. Based on presence of B symptoms (fever, night sweats, weight loss), the patients were categorized into those with B symptoms (presence of B symptoms) and those with A symptoms (absence of B symptoms). Performance status (PS) was assessed according to Eastern Cooperative Oncology Group (ECOG) ${ }^{[11]}$ as follows:PS-0: fully active, able to carry out all pre-disease performances without restriction; PS-1: restricted in physically strenuous activity but ambulatory and able to carry out work of a light or sedentary nature (e.g., light house work, office work); PS-2: ambulatory and capable of all self-care but unable to carry out any work activities; PS-3: capable of only limited self-care, confined to bed or chair more than $50 \%$ of waking hours; PS-4: completely disabled, cannot carry out any self-care, totally confined to bed or chair; and PS-5: dead.

From each patient, venous blood sample $(5 \mathrm{~mL})$ was obtained from the antecubital vein under complete aseptic conditions in EDTA (ethylene-diamine-tetraacetic acid)-contained tube, centrifuged at 1000xg for 10 minutes, and the separated serum is then stored at $-70{ }^{\circ} \mathrm{C}$ for later determination of CA-125.The CA-125 is determined using enzyme immunoassay (EIA) according to Roche Diagnostics Products Ltd (Welwyn Garden City, Hertfordshire, USA). The CA-125 values were expressed in $\mathrm{u} / \mathrm{mL}$, with reference range of $0-35 \mathrm{u} / \mathrm{mL}^{[12]}$.

\section{Statistical Methods:-}

Statistical analyses were done using SPSS (Statistical Package of Social Science) vs. 25. Numerical data were expressed as means, standard deviation (SD), and ranges.Categorical data was expressed as numbers and percentages. Mann Whitney U test was used to compare CA-125 levels among different parameters. Spearman's correlation was used to measure the strength of association between 2 numerical values. The ' $r$ ' is the correlation coefficient, and it ranges from -1 (indicates negative correlation) to 0 (indicates no correlation) to +1 (indicates positive correlation). All $\mathrm{P}$ values were two sided; $\mathrm{P}$ value $<0.05$ was considered to indicate a statisticallysignificant difference ${ }^{[13]}$.

\section{Results:-}

This multi-centers studywas conducted during the period fromOctober, 2017 to August, 2019 included 117 patients with newly-diagnosed non-Hodgkin's lymphoma, 75 males (64.1\%) and 42 females (35.9\%), with a mean age \pm SD of $41.5 \pm 17.6 y e a r s$ (range, $19-63$ years)and a mean BMI \pm SD of $24.1 \pm 8.3 \mathrm{~kg} / \mathrm{m}^{2}\left(\right.$ range, $\left.17.5-31.2 \mathrm{~kg} / \mathrm{m}^{2}\right)$. The frequencies and percentages of studied patients regarding sex, B symptoms, performance status, disease stages, and sites of lesions are shown in table 1 . Out of the 117 included patients, $72(61.5 \%)$ presented with nodal lesions only, $9(7.7 \%)$ presented with extranodal lesions only, and $36(30.8 \%)$ presented with both nodal and extranodal lesions. Collectively, 108 patients $(86.1 \%)$ presented with nodal lesions (72 had nodal lesions only plus 36 had both nodal and extranodal lesions) and 45 patients (13.9\%) presented with extranodal lesions (9 had extranodal lesions only plus 36 had both extranodal and nodal) (table 1).

The mean level of serum CA-125 level \pm SDin all studied patients was $59.2 \pm 17.8 \mathrm{u} / \mathrm{mL}$ (range, $25-539 \mathrm{u} / \mathrm{mL}$ ). Mean serum CA-125 level \pm SD in male patients was $57.1 \pm 16.7 \mathrm{u} / \mathrm{mL}$ and in female patients was $64.3 \pm 20.6 \mathrm{u} / \mathrm{mL}$, with non-significant differences regarding serum CA-125 levels between males and females ( $\mathrm{p}$ value $=0.09$ ). Mean serum CA-125 level \pm SD in patients with PS- 1 was $49.2 \pm 12.7 \mathrm{u} / \mathrm{mL}$, in patients with PS-2 was $62.2 \pm 18.9 \mathrm{u} / \mathrm{mL}$, and inpatients with PS-3 was $161.9 \pm 37.2 \mathrm{u} / \mathrm{mL}$. Mean serum CA-125 levels were significantly higher in patients with PS-3 compared to its levels in patients with PS-2 and in patients with PS-1 (P value $=0.02 ; \mathrm{r}=0.392$ ) (table 2; figure 4).In this study, no patients were presented with PS-0, PS-4, or PS-5. Patients with B symptoms had serum CA-125 level \pm SD of $125.9 \pm 31.2 \mathrm{u} / \mathrm{mL}$, which is significantly higher than its level in patients with A symptoms $(57.2 \pm 18.7 \mathrm{u} / \mathrm{mL})(\mathrm{p}$ value $=0.03)($ table 2 ; figure 2$)$.Serum CA-125 level \pm SD in patients with stage-I disease was $51.7 \pm 15.2 \mathrm{u} / \mathrm{mL}$, stage-II disease was $61.3 \pm 17.6 \mathrm{u} / \mathrm{mL}$, stage-III disease was $93.1 \pm 31.8 \mathrm{u} / \mathrm{mL}$, and stage-IV disease was $167.1 \pm 59.6 \mathrm{u} / \mathrm{mL}$; a significant positive non-linear correlation was noted between disease stages and levels of CA-125, where the advancing the disease staging the increasing the serum CA-125 levels $(\mathrm{p}$ value $=0.04 ; \mathrm{r}=0.491$ ) (table 2; figure 3).

Serum CA-125 level \pm SD in NHL patients with nodal lesions only was $51.7 \pm 16.3 \mathrm{u} / \mathrm{mL}$, in patients with extranodal lesions only was $217.1 \pm 47.9 \mathrm{u} / \mathrm{mL}$, andin patients with both nodal and extranodal lesions was $198.2 \pm 41.7 \mathrm{u} / \mathrm{mL}$. Serum CA-125 levels were significantly higher in patients with extranodal lesions only compared to those with 
nodal lesions only ( $\mathrm{p}$ value $=0.002$ ) and in patients with both nodal and extranodal lesions compared to those with nodal lesions only ( $\mathrm{p}$ value $=0.007$ ), but serum CA-125 levels showed no significant differences in patients with extranodal lesions only compared to those with both nodal and extranodal lesions ( $\mathrm{p}$ value $=0.28$ ) (table 3 ; figure 1 ).

On studying involvement of extranodal sites of lesions separately, the mean serum CA-125 level \pm SD in patients with hepatic lesions with or without nodal lesions was $213.8 \pm 61.6 \mathrm{u} / \mathrm{mL}$, in patients with splenic lesions with or without nodal lesions was $192.1 \pm 42.7 \mathrm{u} / \mathrm{mL}$, in patients with bone marrow lesions with or without nodal lesions was $242.3 \pm 61.6 \mathrm{u} / \mathrm{mL}$, in patients pleural effusion with or without nodal lesions was $251.7 \pm 48.9 \mathrm{u} / \mathrm{mL}$, and in patients with other extranodal lesions (gastric lesions, ascites, or nervous system lesions) with or without nodal lesions was 221.7 $\pm 53.9 \mathrm{u} / \mathrm{mL}$. There were significantly higher CA-125 levels in patients with hepatic lesions, splenic lesions, bone marrow lesions, pleural effusion, and other extranodal lesions compared to patients with nodal lesions only, with p values of $0.007,0.009,0.004,0.002$, and 0.005 , respectively (table 4 ).

Table 1:- Frequency and percentage of studied patients according to various parameters.

Total number $=117$ patients

\begin{tabular}{|l|l|l|l|}
\hline Parameter & Number & Percentage \\
\hline \multirow{3}{*}{ Sex } & Male & 75 & $64.1 \%$ \\
\cline { 2 - 4 } & Female & 42 & $35.9 \%$ \\
\hline \multirow{4}{*}{$\begin{array}{l}\text { Symptoms } \\
\text { status (PS) }\end{array}$} & B symptoms & 43 & $36.8 \%$ \\
\cline { 2 - 4 } & A symptoms & 74 & $63.2 \%$ \\
\hline \multirow{4}{*}{ Stage } & PS-1 & 32 & $27.4 \%$ \\
\cline { 2 - 4 } & PS-2 & 54 & $46.2 \%$ \\
\cline { 2 - 4 } & PS-3 & 31 & $26.4 \%$ \\
\hline \multirow{4}{*}{ Sites of lesions } & Stage I & $18.8 \%$ \\
\cline { 2 - 4 } & Stage II & 32 & $33.3 \%$ \\
\cline { 2 - 4 } & Stage III & 33 & $28.2 \%$ \\
\cline { 2 - 4 } & Stage IV & 23 & $19.7 \%$ \\
\hline & Nodal only & 72 & $61.5 \%$ \\
\cline { 2 - 4 } & Both nodal and extranodal & $36.8 \%$ \\
\cline { 2 - 4 } & Extranodal only & 9 & $7.7 \%$ \\
\hline
\end{tabular}

B symptoms: presence of fever, night sweats, and weight loss.

A symptoms: absence of fever, night sweats, and weight loss.

Table 2:- Serum CA-125 level according to various patients' data Total number $=117$ patients.

\begin{tabular}{|c|c|c|c|}
\hline \multirow{2}{*}{\multicolumn{2}{|c|}{$\begin{array}{l}\text { Parameter } \\
\text { All studied patients }(\mathrm{n}=117)\end{array}$}} & CA-125 level $(\mathrm{u} / \mathrm{mL})($ mean \pm SD $)$ & p value \\
\hline & & \multicolumn{2}{|l|}{$59.2 \pm 17.8$ (range: $25-539 \mathrm{u} / \mathrm{mL})$} \\
\hline \multirow[t]{2}{*}{ Sex } & Male $(n=75)$ & $57.1 \pm 16.7$ & \multirow[t]{2}{*}{0.09} \\
\hline & Female $(n=42)$ & $64.3 \pm 20.6$ & \\
\hline \multirow{3}{*}{ Performance status (PS) } & PS-1 $(n=32)$ & $49.2 \pm 12.7$ & \multirow{3}{*}{0.02} \\
\hline & PS-2 $(n=54)$ & $62.2 \pm 18.9$ & \\
\hline & PS-3 $(n=31)$ & $161.9 \pm 37.2$ & \\
\hline \multirow[t]{2}{*}{ B symptoms } & Yes $(n=43)$ & $125.9 \pm 31.2$ & \multirow[t]{2}{*}{0.03} \\
\hline & $\operatorname{No}(n=74)$ & $57.2 \pm 18.7$ & \\
\hline \multirow[t]{4}{*}{ Stage } & Stage I $(n=22)$ & $51.7 \pm 15.2$ & \multirow{4}{*}{0.04} \\
\hline & Stage II $(n=39)$ & $61.3 \pm 17.6$ & \\
\hline & Stage III $(\mathrm{n}=33)$ & $93.1 \pm 31.8$ & \\
\hline & Stage IV $(n=23)$ & $167.1 \pm 59.6$ & \\
\hline
\end{tabular}

$\mathrm{n}$ : number of patients SD: standard deviation.

Table 3:- Serum CA-125 levels according to sites of lesions Total number $=117$ patients

\begin{tabular}{|c|c|c|c|c|}
\hline Site of lesion & CA-125 level $(\mathrm{u} / \mathrm{mL})($ mean \pm SD $)$ & $\mathbf{P}^{*}$ value & $\mathbf{P}^{\$}$ value & $\mathbf{P}^{\#}$ value \\
\hline Nodal only $(n=72)$ & $51.7 \pm 16.3$ & \multirow{3}{*}{0.002} & \multirow{3}{*}{0.007} & \multirow{3}{*}{0.28} \\
\hline Extranodal only $(n=9)$ & $217.1 \pm 47.9$ & & & \\
\hline Both nodal and extranodal $(\mathrm{n}=36)$ & $198.2 \pm 41.7$ & & & \\
\hline
\end{tabular}


$\mathrm{P}^{*}$ value: extranodal lesionsonly compared to nodal lesions only.

$\mathrm{P}^{\$}$ value: both nodal and extranodal lesions compared to nodal lesions only.

$\mathrm{P}^{\#}$ value: both nodal and extranodal lesions compared to extranodal lesions only

$\mathrm{n}=$ number $\quad \mathrm{SD}$ : standard deviation.

Table 4:- Serum CA-125 levels according to presence of extranodal lesions. Total number $=117$ patients.

\begin{tabular}{|c|c|c|}
\hline Parameters & CA-125 level $(\mathrm{u} / \mathrm{mL})$ mean \pm SD & P value \\
\hline \multicolumn{3}{|c|}{ Hepatic lesion* versus nodal lesions only } \\
\hline Hepatic lesion* $(n=29)$ & $213.8 \pm 61.6$ & \multirow[t]{2}{*}{0.007} \\
\hline Nodal lesions only $(\mathrm{n}=72)$ & $56.3 \pm 19.7$ & \\
\hline \multicolumn{3}{|c|}{ Spleen lesion* versus nodal lesions only } \\
\hline Spleen lesion* $(n=35)$ & $192.1 \pm 42.7$ & \multirow[t]{2}{*}{0.009} \\
\hline Nodal lesions only $(\mathrm{n}=72)$ & $56.3 \pm 19.7$ & \\
\hline \multicolumn{3}{|c|}{ Bone marrow lesion* versus nodal lesions only } \\
\hline Bone marrow lesion* $(n=13)$ & $242.3 \pm 61.6$ & \multirow[t]{2}{*}{0.004} \\
\hline Nodal lesions only $(\mathrm{n}=72)$ & $56.3 \pm 19.7$ & \\
\hline \multicolumn{3}{|c|}{ Pleuraleffusion* versus nodal lesions only } \\
\hline Pleural effusion* $(n=11)$ & $251.7 \pm 48.9$ & \multirow[t]{2}{*}{0.002} \\
\hline Nodal lesions only $(\mathrm{n}=72)$ & $56.3 \pm 19.7$ & \\
\hline \multicolumn{3}{|c|}{ Other ${ }^{\#}$ extranodal lesions versus nodal lesions only } \\
\hline Other $^{\#}$ extranodal lesions* $(\mathrm{n}=9)$ & $221.7 \pm 53.9$ & \multirow[t]{2}{*}{0.005} \\
\hline Nodal lesions only $(\mathrm{n}=72)$ & $56.3 \pm 19.7$ & \\
\hline
\end{tabular}

*extranodal lesion alone plus extranodal associated with nodal lesions

\# other extranodal lesions include gastric lesions, ascites, and nervous system lesions.

$\mathrm{n}$ : number SD: standard deviation

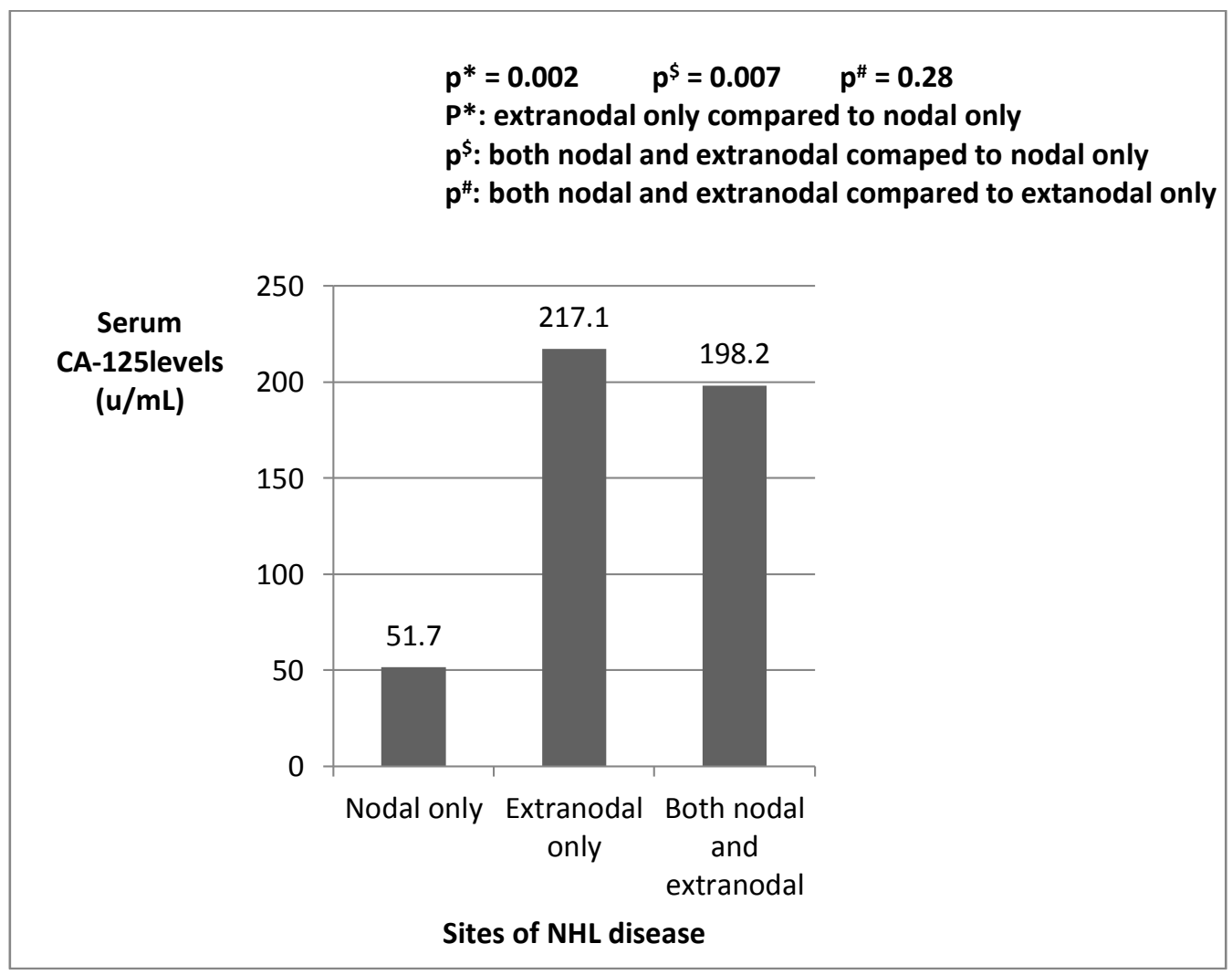

Figure 1:- Serum CA-125 levels according to sites of NHL lesions. 


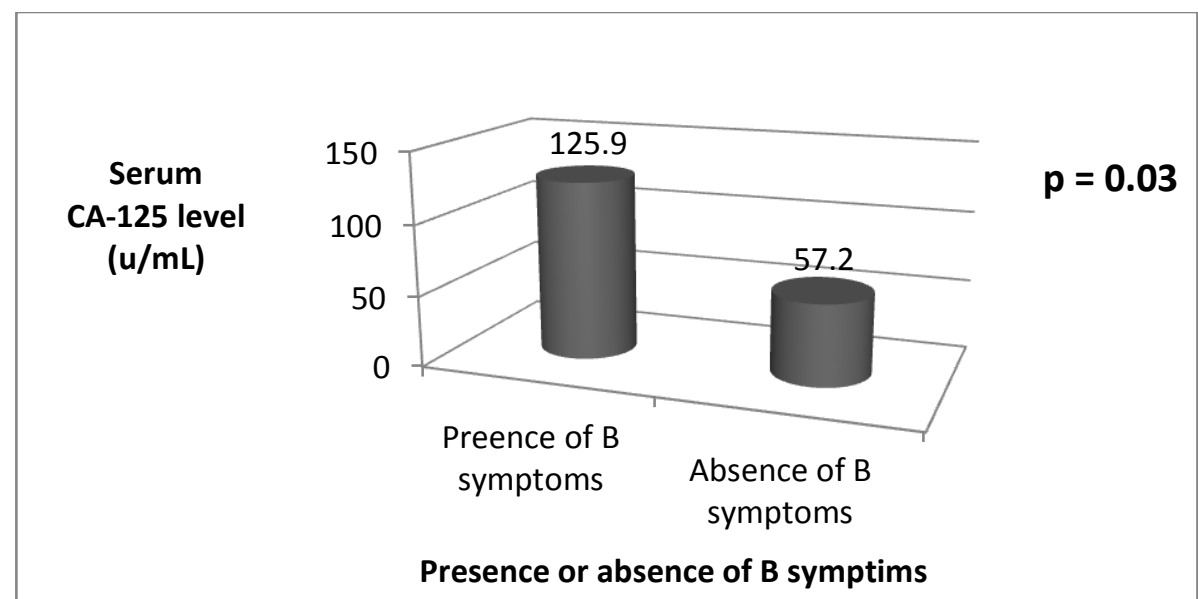

Figure 2:- Serum CA-125 levels according to B symptoms.

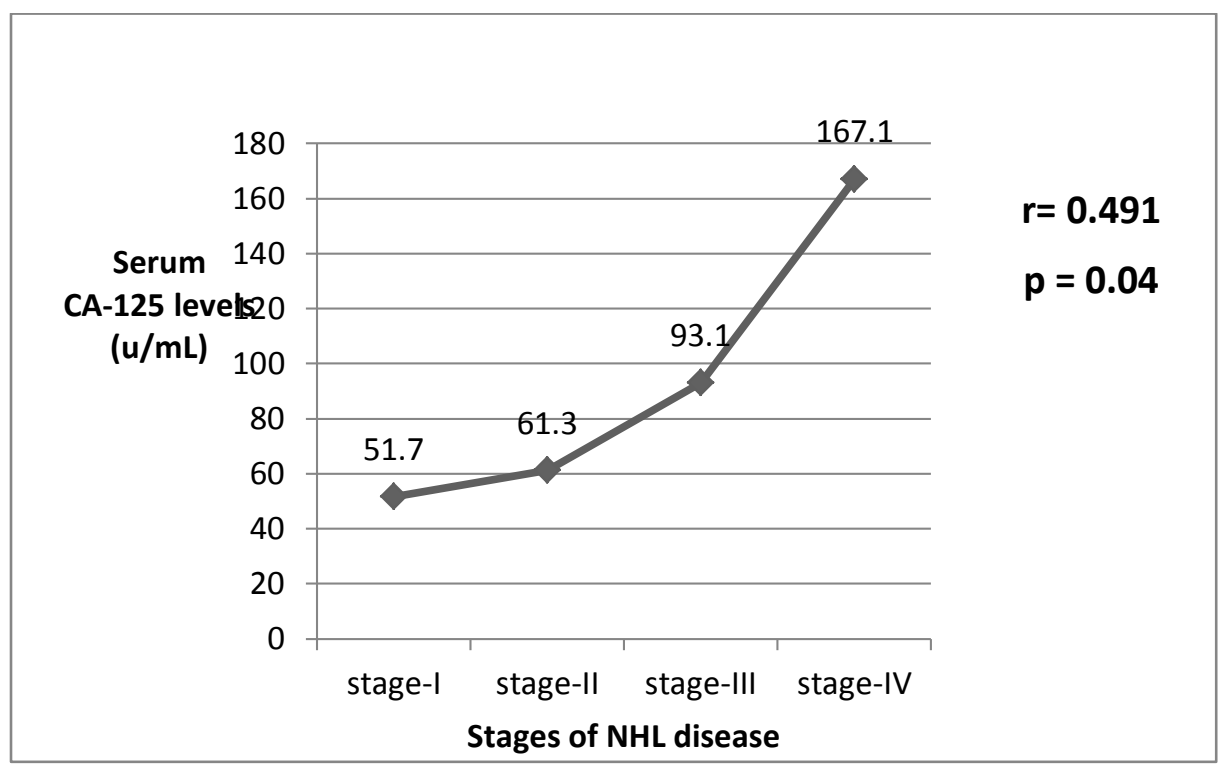

Figure 3:- Serum CA-125 levels according to stages of NHL disease.

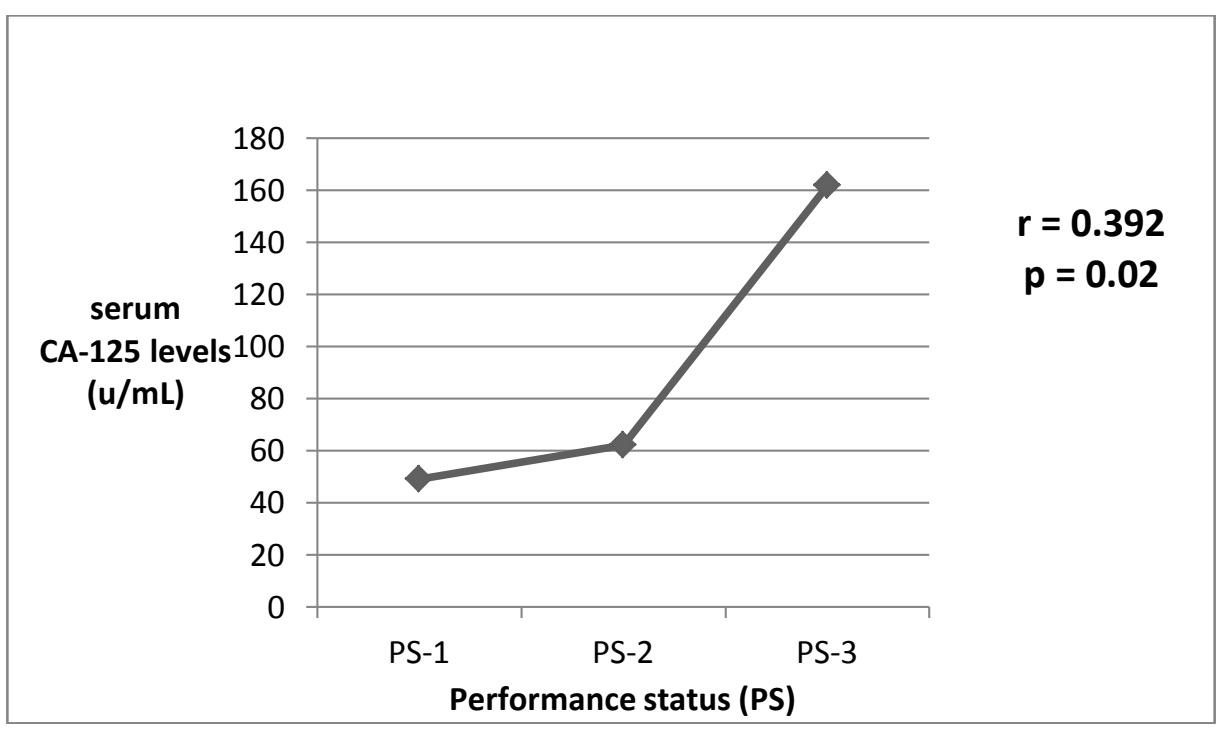

Figure 4:- Serum CA-125 levels according to performance status. 


\section{Discussion:-}

Serum CA-125 level has been used as a tumor marker, particularly for follow-up of ovarian cancer; however, elevated CA-125 level has been reported in other malignancies including lymphomas ${ }^{[14]}$.A total of $117 \mathrm{NHL}$ patients, 75 males $(64.1 \%)$ and 42 females (35.9\%), were studied in this work. Mean serum CA-125 level for the all studied patients was $59.2 \pm 17.8 \mathrm{u} / \mathrm{mL}$ (reference range of CA-125 is $0-35 \mathrm{u} / \mathrm{mL}$ ). Based on the uppermost limit of CA125 reference range, which is $35 \mathrm{u} / \mathrm{mL}, 46.2 \%$ (54 out of 117) of NHL patients in the current study had CA-125 levels higher than the upper limit of the CA-125 reference range, whereas the remaining 53.8\% of patients had CA125 values within the reference range. Similarly, Memar et al. ${ }^{[2]}$ reported that $43 \%$ of their patients had CA-125 levels lower than a cut-off point of $35 \mathrm{u} / \mathrm{mL}$.In a study by Abdel Gawad and Shafik, ${ }^{[15]}$ the serum CA-125 levels were elevated in $55 \%$ of patients.Jamal et al. ${ }^{[16]}$ also reported elevated CA-125 levels in $46 \%$ of patients with aggressive NHL and in $43 \%$ of patients with low-grade NHL. On the other hand, Abdolmonem et al. ${ }^{[17]}$ reported elevated serum CA-125 levels above the cut-off value of $30.1 \mathrm{u} / \mathrm{mL}$ in $63.3 \%$ of NHL patients, which is higher than our results; this difference could be attributed to that Abdolmonem et al ${ }^{[17]}$ studied NHLs in pediatric patients but our patients were adults and that the CA-125 cut-off value in Abdolmonem et al. study was $30.1 \mathrm{u} / \mathrm{ml}$ but in current study it was $35 \mathrm{u} / \mathrm{ml}$.

In current study, no significant differences were reported regarding serum CA-125 levels in males compared to females $\left(\mathrm{p}\right.$ value $=0.09$ ). Memar et al. ${ }^{[2]}$ also reported no significant differences of CA-125 levels regarding genders.In present study, patients with PS-3 had significantly higher CA-125 levels compared to those with PS-1 (p value $=0.02$ ). Similarly, Memar et al. ${ }^{[2]}$ reported significant differences in IPI score and stage of the disease between patients with serum CA-125 level less than $35 \mathrm{u} / \mathrm{mL}$ and patients with CA-125 levels more than $35 \mathrm{u} / \mathrm{mL}$. In 1998,Lazzarino et al. ${ }^{[9]}$ reported a higher serum CA-125 level in NHL patients with advanced stage of disease, aggressive histology, and extranodal extension.

In present work, significantly higher serum CA-125 levels were observed in NHL patients presented with B symptoms compared to those without(p value 0.03 ). Memar et al. ${ }^{[2]}$ also reported a significant association between high CA-125 levels and B symptoms.Incurrent study, advancement of the NHL disease stages were associated with higher serum CA-125 levels, where patients with stage-IV disease had significantly higher CA-125 levels compared to those with stage-II and stage-I disease (p value 0.04). Consistently, Abdolmonem et al. ${ }^{[17]}$ found a statistically significant higher CA-125 level in advanced stages (stage-III, stage-IV) pediatric NHL patients compared to stageII. Also, in a study by Abdel Gawad and Shafik, ${ }^{[15]}$ the CA-125 and LDH levels were highest in stage-IV disease, followed by stage-III, then stage-II, and lowest in stage-I. Additionally, Memar et al. ${ }^{[2]}$ found significant correlation between high CA-125 levels and stages of NHL disease. Also, Dilek et al. ${ }^{[18]}$ reported that serum CA-125 can be used as a predictive prognostic marker in advanced NHLs and that serum CA-125 level could be a reliable biological marker for staging of patients with NHLs.In a study by Bairey et al., ${ }^{[1]}$ serum CA-125 can be used as a reliable marker for staging and assessing tumor activity in NHLs.

In present study, patients with extranodal lesions only as well as those with both nodal and extranodal lesions had significantly higher serum CA-125 levels compared to those with nodal lesions only, with p values of 0.002 and 0.007, respectively; but, the CA-125 levels in patients with extranodal lesions only were statistically insignificant compared to its levels in those with both nodal and extranodal lesions ( $\mathrm{p}$ value $=0.28$ ). In agreement with these results, Prochazka et al. ${ }^{[19]}$ reported a correlation of high serum CA-125 with advanced disease, mediastinal involvement, bulky tumors, effusion and/or extranodal extension in patients with NHLs. Also,Lokanathan et al. ${ }^{[20]}$ and Abdel-Gawad and Shafik ${ }^{[15]}$ showed association between CA-125 levels and extra-nodal involvement, advanced stage and elevated serum LDH level ${ }^{[15]}$.

In current study, on considering the lymph node groups individually, the CA-125 levels showed no significant differences with positive or negative affection of an individual lymph node groups.In contrast, Lazzarino et al. ${ }^{[9]}$ found that high serum CA-125 levels were correlated with mediastinal and/or abdominal involvement. In the current study, significantly higher CA-125 levels were found in NHL patients with hepatic lesions, splenic lesions, bone marrow lesions, pleural effusion, and other extranodal lesions (gastric lesions, ascites, nervous system lesions) compared to those with nodal lesions only. Concurrently, Lazzarino et al. ${ }^{[9]}$ reported higher serum CA-125 levels in NHL patients with high tumor mass, extranodal lesions and effusions, reflecting the reaction of mesothelial cells to the tumor. 


\section{Conclusion and recommendation:-}

In NHL patients, higher serum CA-125 levels were observed with advanced NHLstages III and IV, presence of extranodal lesions, and presence of B symptoms. Thus, serum CA-125 level is recommended to be checked in NHL patients with nodal lesions, particularlythose with advanced stages diseaseand B symptoms, at their presentation, and patients with significantly higher serum CA-125 levels should be carefully searched for the possible presence of clinically undetected extranodal lesions. Also, further studies are recommended to set a cut-off point for the serum CA-125 levels to be used as an indicator for the presence of extranodal NHL lesions.

\section{References:-}

1. Bairey O, Blickstein D, Stark P, Prokocimar M, Nativ H, Kirgner I and Shaklai M: Serum CA 125 as a prognostic factor in non-Hodgkin's lymphoma. Leuk Lymphoma, 2003; 44(10); 1733-1738.

2. Memar B, Aledavood A, Shahidsales S, Ahadi M, Farzadnia M, Raziee H, Noori S, Amouian S and Mohtashami S: The prognostic role tumor marker CA-125 in B-cell non-Hodgkin's lymphoma. Iran J Cancer Prev., 2015; 8(1): 42-46.

3. International Non-Hodgkin's lymphoma Prognostic Factor Project: Apredictive model for aggressive nonHodgkin's lymphoma. N Engl J Med., 1993; 329: 987-994.

4. Sanjeev G and Bela G: Evaluation of CA-125 as a prognostic marker in patients with non-Hodgkin's lymphoma. Internal Journal of Medical and Health Research; 2017; volume 3; Issue 4; page 113-115.

5. Fauzia A and AbdusSamad S: Association of serum CA-125 levels with non-Hodgkin's lymphoma. Pak J Physiol, 2017; 13(1); 54-56.

6. Rump A, Morikawa Y, Tanaka M, Minami S, Umesaki N, and Takeuchi M: Binding of ovarian cancer antigen CA125/MUC16 to mesothelin mediates cell adhesion. J BiolChem, 2004; 279; 9190-9198.

7. Sanusi A, Zweers M, Weening J, de Waart DR, Struijk D and Krediet R: Expression of cancer antigen 125 by potential mesothelial cells is not influenced by duration or peritoneal dialysis. Perit Dial Int., 2001; 21(5); 495500 .

8. Pui T and Ludwig C: CA-125 a tumor marker in NHL. J of Clinical Oncology, 1995; 13: 1827.

9. Lazzarino M, Orlandi E, Klersy C, Astori C, Brusamolino E, and Corso A: Serum CA 125 is of clinical value in the staging and follow-up of patients with non-Hodgkin's lymphoma: correlation with tumor parameters and disease activity. Cancer, 1998; 82: 576-582.

10. Cheson B, Fisher R and Barrington S: Guideline recommendations for initial evaluation, staging, and response of Hodgkin and non-Hodgkin lymphoma: the Lugano classification. J ClinOncol, 2014; 32(27); 3059-3068.

11. Oken M, Creech R, Tormey D, Horton J, Davis T, McFadden E, and Carbone P: Toxicity and response criteria of the Eastern Cooperative Oncology Group. Am J ClinOncol, 1982; 5; 649-655.

12. Kubonishi I, Bandobashi K, and Miyoshi I: High serum levels of CA125 and IL-6 in patients with Ki-I lymphoma. Br J Hematol, 1997; 98; 452.

13. Dawson-Saunders B and Trapp GT (editors): Basic and Clinical Biostatistics. Norwalk, Connecticut, Lange Medical Books, Appleton \& Lange, 1994, page 123.

14. Harris N, Jaffe E, Armitage J, and Shipp M: Lymphoma classification: from R.E.A.L. to WHO and beyond. Cancer: Principles and Practice of Oncology Updates; 1999; 13 (3): 1-14.

15. Abdel Gawad I and Shafik M: CA-125, a New Prognostic Marker for Aggressive NHL. Journal of Egyptian Nat. Cancer Inst., 2009; vol. 21. No. 3, September 2009; 209-217.

16. Jamal Z, Osamah H, Walid B, and Shmuel Z: Serum CA-125: A tumor marker for monitoring response to treatment and follow-up in patients with non-Hodgkin's lymphoma. Oncologist, 2004; 9(4): 417-421.

17. Abdelmonem A, Amany S, Maysa T, Saleh I, and Saadia I: Serum CA-125 as a diagnostic and prognostic in pediatric lymphoma. J Med Sci., 2007; 7(7): 1192-1196.

18. Dilek I, Ayakta H, Demir C, Meral C, and Ozturk M: CA-125 levels in patients with non-Hodgkin's lymphoma and other hematologic malignancies. Clin Lab Haematol., 2005; 27(1): 51-55.

19. Prochazka V, Faber E, Raida L, Kapitanova Z, Langova K, Indark K, and Papajik T: High serum carbohydrate antigen-125 (CA-125) level predicts poor outcome in patients with follicular lymphoma independently of the FLIPI score. Int J Haematol., 2012; 96(1): 58-64.

20. Lokanathan V, Gupta G, Ghalaut V, Ghalaut P, and Mahor A: CA-125 in non-Hodgkin's lymphoma and its association with severity of the disease. Am MultidiscipInt Res J., 2015; 2(4): 1-6. 